\title{
Topical azithromycin or ofloxacin for endophthalmitis
}

\section{Michael W Stewart Michael L Stewart}

Department of Ophthalmology, Mayo Clinic, Jacksonville, FL, USA
Correspondence: Michael W Stewart Department of Ophthalmology, 4500 San Pablo Rd, Jacksonville, FL 32224, USA

Tel + I 9049532232

Fax + I 9049537040

Email stewart.michael@mayo.edu

\author{
This article was published in the following Dove Press journal: \\ Clinical Ophthalmology \\ 28 December 2012 \\ Number of times this article has been viewed
}

The recently published study by Romero-Aroca et $\mathrm{al}^{1}$ raises interesting questions regarding the effect of choice of topical antibiotic (azithromycin versus ofloxacin) on the incidence of endophthalmitis following intravitreal injections. However, important conclusions advanced by the authors deserve further discussion. First, the authors state that use of azithromycin leads to significantly fewer cases of post-injection endophthalmitis than does the use of ofloxacin. Their prospective series shows a lower endophthalmitis rate in eyes treated with azithromycin (two cases in 4045 injections, $0.049 \%$ ) than in eyes treated with ofloxacin (five cases in 4151 injections, $0.12 \%$ ). They calculate a relative risk of 2.37 , and conclude that this was statistically significant (confidence interval 1.37-3.72; $P<0.001$ ).

We believe that this conclusion is wrong because of errors in the statistical computations. When the endophthalmitis incidence rates are compared using both the Chi-square and two-proportion z-tests, the differences between the cohorts are minimal and far from clinically significant (Chi-square 1.211, two-sided z-statistic 1.10; $P=0.27$ for both tests). In fact, for these observed rates to yield a significant difference, a trial with 12,000 injections in each group (three times the size reported by the authors) would be necessary. Therefore, with the data presented, it is not possible to detect a meaningful difference in endophthalmitis rates between the two drugs.

Contrary to the authors' assertion, many retrospective and prospective studies have reported the incidence of endophthalmitis after injections. In the largest prospective age-related macular degeneration trials to date (VIEW 1 and 2), ${ }^{2}$ six cases of endophthalmitis occurred after $27,112(0.022 \%$ or one in 4519$)$ injections in 2457 patients. This endophthalmitis rate is similar to the rates reported in the two largest published series of injections (one in 4059 patients and the other in 8617 patients). . $^{3,4}$ This leads to the second important point, ie, the authors performed their study under the assumption that prophylactic topical antibiotics lower the incidence of post-injection endophthalmitis. However, to date, no studies have shown that use of prophylactic antibiotics lowers the rate of post-injection endophthalmitis. No differences in antibiotic-related endophthalmitis rates were identified in the largest retrospective series, and as a result, many surgeons have abandoned such use of antibiotics.

The conclusions advanced by Romero-Aroca et al also have significant financial implications. Recent data show that more than 220,000 patients (2008 Medicare data) in the US receive intravitreal injections each year. ${ }^{5}$ Single bottles of azithromycin and ofloxacin cost $\$ 108$ and $\$ 18$, respectively, and if these were prescribed once yearly for 
each patient receiving injections, the total cost would range from $\$ 3.96$ million to $\$ 23.76$ million. Given that neither drug has been shown to lower the rate of endophthalmitis, this probably represents a significant waste of money. We applaud the interest of Romero-Aroca et al in endophthalmitis, but we must challenge both the conclusions of their paper and the overall effectiveness of post-injection antibiotics.

\section{References}

1. Romero-Aroca P, Sararols L, Arias L, Casaroli-Marano RP, Bassaganyas F. Topical azithromycin or ofloxacin for endophthalmitis prophylaxis after intravitreal injection. Clin Ophthalmol. 2012;6:1595-1599.
2. Regeneron. Bayer and Regeneron report positive top-line results of two Phase 3 studies with VEGF Trap-Eye in wet age-related macular degeneration. Available from: http://investor.regeneron.com/releasedetail. cfm?ReleaseID=552099. Accessed April 13, 2012.

3. Moshfeghi AA, Rosenfeld PJ, Flynn HW Jr, et al. Endophthalmitis after intravitreal anti-vascular endothelial growth factor antagonists: a six-year experience at a university referral center. Retina. 2011;31(4):662-668.

4. McCannel CA. Meta-analysis of endophthalmitis after intravitreal injection of anti-vascular endothelial growth factor agents: causative organisms and possible prevention strategies. Retina. 2011;31(4):654-661.

5. Brechner FJ, Rosenfeld PJ, Babish JD, Caplan S. Pharmacotherapy for neovascular age-related macular degeneration: analysis of the 100\% 2008 medicare fee-for-service part B claims file. Am J Ophthalmol. 2011;151(5):887-895. 


\section{Author response}

\section{Pedro Romero-Aroca}

Department of Ophthalmology, Hospital Universitari Sant Joan, Universidad Rovira i Virgili, Reus, Spain

Correspondence: Pedro Romero-Aroca Department of Ophthalmology, Hospital Universitari Sant Joan, Universidad Rovira i Virgili, Avda Josep Laporte 2, 43204 Reus, Spain Email romeropere@gmail.com

On behalf of the study investigators, I thank the authors for the above letter and the interest they have shown in our study. We agree with the authors that use of topical antibiotics to prevent endophthalmitis after intravitreal injections generates important doubts. The literature currently indicates a low incidence of endophthalmitis after intravitreal injection, but we must remember that all clinical practice guidelines, in particular those of the Spanish Society of Retina and Vitreous (SERV) ${ }^{1}$ and the Royal College of Ophthalmologists, ${ }^{2}$ presently recommend postoperative use of topical antibiotics. It should also be borne in mind that the risk of endophthalmitis following intravitreal injection varies greatly according to local geography, eg, there is a higher incidence of endophthalmitis in the Mediterranean countries than in the Nordic countries. Even in a multicenter study like ours, the incidence of endophthalmitis varies according to the center where patients are being treated and according to their socioeconomic status.

We use topical antibiotics in line with SERV recommendations. Topical ofloxacin is the preferred agent, but the number of resistant bacteria has increased dramatically ${ }^{3}$ in our hospital, resistance of Gram-positive bacteria to ofloxacin exceeds $40 \%$ and resistance of Gram-negative bacteria is around $46 \%$, according to data from 2011 . These data are of considerable concern, given that we are required to use an agent of doubtful efficacy with the potential to promote growth of resistant organisms in the conjunctiva of the eye.

It should be noted that topical moxifloxacin, a fourthgeneration quinolone, had been available in Spain for barely one year after completion of our study. I recall here that, in our study, we indicated an incidence of adverse reactions important in the group of patients with previous azithromycin segment 14 cases of disturbance, including two cases of punctate keratitis, but no cases in the ofloxacin group.
In our study, there were two cases of endophthalmitis $(0.049 \%)$ in the azithromycin group and five cases $(0.122 \%)$ in the ofloxacin group and application of the T-Student test and Fisher test did detect a statistically significant difference between the groups. It should also be noted that an odds ratio of 2.37 is at the limit of statistical significance and that an odds ratio $>2.0$ is significant, demonstrating an advantage in the azithromycin group versus the ofloxacin group. This is not a relative risk ratio, and if we had determined the relative risk, it would probably have been lower and barely significant, as indicated in the above letter. Stewart and Stewart suggest that our results should not be taken as conclusive because of the small patient numbers with endophthalmitis and that further studies should be performed. However, it should be noted that when discussing the potential advantages of one drug over another, we stated that "... the study precludes any categorical confirmation of the advantage of one drug over the other in the prophylaxis of endophthalmitis after intravitreal injection."

Instead of questioning the study, it is suggested that if another case of endophthalmitis appeared in the azithromycin group, the statistical significance would be negligible given the small difference in numbers between the two groups of cases. Our interest was in finding an antibiotic that could be used effectively after intravitreal drug injection and take into account the recommendations made by SERV in our country. However, given the widespread practice of using antibiotics to treat conjunctivitis we are concerned about the emergence of resistance, as has occurred with ofloxacin. With regard to the issue of cost-effectiveness, it should be noted that ofloxacin has a resistance index of over $40 \%$ in our country, which invalidates its effectiveness in prophylactic use.

Finally, the study investigators are working in an environment where the SERV recommendation is to use topical antibiotics after intravitreal injections, and if we do not do so we are not legally covered. Moreover, if we use a quinolone (ofloxacin) with a resistance index higher than $40 \%$, we are not providing useful antibiotic prophylaxis, leaving us again without legal cover. Therefore, our aim is to find a more effective drug for prophylaxis. We cannot say that this drug is necessarily azithromycin, but we feel that it appears to be superior to ofloxacin. Clearly, we need more conclusive study data before organizations like SERV would discourage the use of topical antibiotics in this indication. 


\section{References}

1. Sociedad Española de Retina y Vítreo. Manejo de las inyecciones intravítreas. Guías de Práctica Clínica de la SERV. 2009. Available from: http://www.serv.es. Accessed November 19, 2012.

2. Royal College of Ophthalmologists. Guidelines for intravitreal injections procedure, 2009. London, UK: Royal College of Ophthalmologists; 2009. Available from: http://www.rcophth.ac.uk. Accessed November 19, 2012.
3. Baquero F, Martínez-Beltrán J, Cantón R. Criteria of the MENSURA group for the definition of the critical points of sensitivity to antibiotics. Enferm Infecc Microbiol Clin. 1998;16(2):85-92. Spanish.

\section{Publish your work in this journal}

Clinical Ophthalmology is an international, peer-reviewed journal covering all subspecialties within ophthalmology. Key topics include: Optometry; Visual science; Pharmacology and drug therapy in eye diseases; Basic Sciences; Primary and Secondary eye care; Patient Safety and Quality of Care Improvements. This journal is indexed on
PubMed Central and CAS, and is the official journal of The Society of Clinical Ophthalmology (SCO). The manuscript management system is completely online and includes a very quick and fair peer-review system, which is all easy to use. Visit http://www.dovepress.com/ testimonials.php to read real quotes from published authors. 